\title{
Diffusion coupling between trace and major elements and a model for calculation of magma residence times using plagioclase
}

\author{
F. Costa ${ }^{1,2}$, S. Chakraborty ${ }^{3}$ and R. Dohmen ${ }^{3}$ \\ ${ }^{1}$ Section des Sciences de la Terre, Université de Genève, 13 Rue des Maraîchers, 1211, \\ Geneva, Switzerland \\ ${ }^{2}$ Institut des Sciences de la Terre d'Orléans-CNRS Université d'Orléans, UMR 6113, 1A Rue \\ de la Ferollerie, 45071, Orléans, France \\ ${ }^{3}$ Institut für Geologie, Mineralogie und Geophysik, Ruhr-Universität Bochum, 44780, \\ Bochum, Germany
}

\begin{abstract}
Residence times of plagioclase crystals in magma reservoirs can be determined by modeling the compositional zoning of trace elements in these crystals. We present a formulation to model diffusion of trace elements in plagioclase paying special attention to certain thermodynamic and kinetic aspects. In particular, we account for the compositional dependence on anorthite content of the chemical potential and diffusion coefficients of trace elements (e.g., Mg), the choice of suitable boundary conditions and potential effects of diffusion in more than one dimension. We show that contrary to intuition, diffusive fluxes of trace elements may be coupled to major element concentration gradients, and ignoring such coupling can lead to incorrect estimates of timescales. We illustrate application of the model using plagioclase crystals from a suite of gabbroic xenoliths from a Holocene dacitic lava flow of Volcán San Pedro (Chilean Andes, $36^{\circ} \mathrm{S}$ ). The inferred timescale for metasomatism of the xenoliths by evolved liquids is on the order of 100 (30 to 148) yr and serves to illustrate how trace element zoning in plagioclase provides a window into timescales of magmatic processes inaccessible by isotopic or other methods.
\end{abstract}

\section{Introduction}

Lifetimes of magma reservoirs and the rates of igneous differentiation are important parameters in understanding the thermal and chemical evolution of the crust. Furthermore, these are key concerns in volcanic hazard management and mitigation. Isotopic methods have been used to assess these parameters, but short timescales on the order of a few hundred years or less are not ideally suited for the resolution of isotopic methods, even if U-Th and Ra-Th isotopic disequilibria have provided major insights into processes approaching the upper end of this temporal spectrum (e.g., Volpe and Hammond 1991; Schaefer et al 1993; Zellmer et al 2000; Cooper et al 2001 and Sigmarsson et al 2002. A tool that is complementary to these techniques is kinetic modeling. It relates timescales directly to specific processes and is capable of accessing the shorter timescales of interest (e.g., Nakamura 1995; Zellmer et al 1999 and Pan and Batiza 2002. A strength of the kinetic approach is that it can be applied to individual grains such that it is possible to test reproducibility and obtain insight into the statistical distribution of the retrieved parameters. In this regard, plagioclase is perhaps the most important group of minerals for a number of reasons: (1) it is one of the commonest igneous minerals, (2) it crystallizes practically over the entire temperature and compositional range of igneous differentiation, and (3) it shows pronounced compositional zoning, spanning 
a wider fraction of the total solid solution series than any other mineral group. Indeed, these latter two aspects have been widely utilized, sometimes in conjunction with plagioclase-melt partition coefficients, to study magmatic processes (e.g., Blundy and Shimizu 1991; Singer et al 1995; Brophy et al 1996; Davidson and Tepley 1997; Bindeman et al 1999 and Ginibre et al 2002. This listing of favorable characteristics of plagioclase can be extended by recognizing that diffusion rates (D) of different elements in plagioclase can differ by up to seven orders of magnitude at a given set of conditions (e.g., $\mathrm{D}_{\mathrm{Mg}} \sim 100 \times \mathrm{D}_{\mathrm{Sr}} \sim 100,000 \times \mathrm{D}_{\mathrm{NaSi}-\mathrm{CaAl}}$ [Grove et al 1984; Giletti and Casserly 1994 and LaTourrette and Wasserburg 1998] at $1000^{\circ} \mathrm{C}$ ), so that different elements can record different aspects of the thermal history experienced by a plagioclase crystal. Modeling the differing degrees of modification of compositional zoning of various elements in one crystal provides a unique tool to constrain timescales of processes in a magma chamber. This potential was recognized by Zellmer et al. (1999), who provided a model to treat $\mathrm{Sr}$ concentration profiles in plagioclase to constrain residence times. However, the compositional variability and large range of diffusion rates also imply that special care is required to address these aspects in kinetic modeling using plagioclase compositions. In particular, an adequate kinetic model needs to consider the following: (1) under any given ambient condition, the chemical potential of trace elements (e.g., $\mathrm{Mg}, \mathrm{Sr}, \mathrm{Ba}$ ) in plagioclase crystals of different anorthite contents (An) are very different (e.g., Blundy and Wood 1991 and Bindeman et al 1998, (2) the diffusion rates of trace elements in plagioclase crystals of different An content can be very different (Sr, Ba, K; Cherniak and Watson 1994; Giletti and Casserly 1994; Giletti and Shanahan 1997 and Cherniak 2002, (3) the choice of proper boundary conditions, that closely reflect natural conditions, and (4) possible two-dimensional diffusion effects in elongate prismatic grains, depending on grain size.

In the following, we develop a set of generalized equations for kinetic modeling that incorporates these considerations using the specific example of $\mathrm{Mg}$ in plagioclase. It is found that diffusive fluxes of trace elements may be strongly coupled to major element concentration gradients, and that ignoring such coupling can lead to incorrect estimates of timescales. The outline of the article is as follows: after the mathematical derivation and discussion of the model parameters, we present some results of model calculations to illustrate the behavior of trace elements in such systems. Next, we address additional issues that need to be tackled for modeling natural crystals, and finally, we illustrate the application of the model to plagioclase crystals from gabbroic crustal xenoliths found within Holocene dacitic lava flows of Volcán San Pedro (Tatara San Pedro volcanic complex, $36^{\circ} \mathrm{S}, 71^{\circ} \mathrm{W}$; Singer et al 1997; Dungan et al 2001 and Costa et al 2002. The inferred timescales for metasomatism of the xenoliths by evolved liquids in crustal magma chambers on the order of $100 \mathrm{yr}$ serve to illustrate how this approach provides a window into timescales inaccessible by isotopic or other methods.

\section{Diffusion model}

\subsection{Equilibrium distributions, driving forces, and boundary conditions}

The development and evolution of compositional profiles (e.g., An content) within a plagioclase crystal depends on intensive thermodynamic variables such as temperature and the composition of the melt from which the crystal is growing. The trace element composition (e.g., Mg content) depends, in addition, on the An content of the plagioclase itself. After formation of the core of a plagioclase crystal (Fig. 1a), either the liquid composition or temperature (or some other intensive variable such as pressure) or both might change, so that the next increment of plagioclase that grows has a different major and trace element 
composition (Fig. 1b). Diffusion rates for NaSi-CaAl exchange in plagioclase are exceedingly slow (Grove et al 1984 and Liu and Yund 1992) such that the An profile, once formed, remains essentially unmodified by subsequent diffusion under most geological circumstances. However, the same does not necessarily apply for all trace elements, as these may equilibrate by diffusion to varying extents. The crucial questions are: (1) what is the final "equilibrium" state that the elements strive to achieve under these circumstances?, (2) what are the driving forces for diffusion of a trace element in plagioclase?, and (3) under what boundary conditions does this diffusion occur?. We address these three points in sequence below.
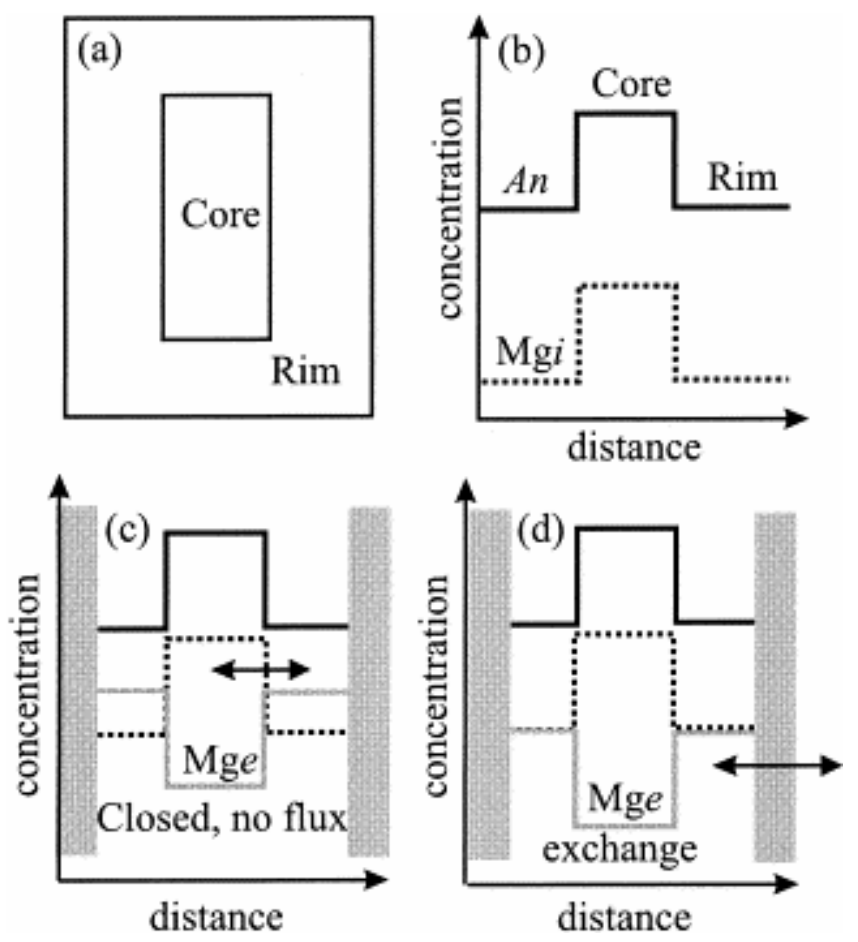

Fig. 1. Schematic illustration of major and trace element zoning in a plagioclase crystal and how the $\mathrm{Mg}$ diffusive equilibrium profiles depend on boundary conditions. (a) Cross section of a crystal showing rim and core with very different major and trace element compositions. (b-d) Concentration profiles that would be measured on a cross section through the crystal such as the one shown in (a). (b) Mgi is the initial Mg profile before diffusion. The large gradient in $\mathrm{Mg}$ concentration between the rim and the core will drive diffusion. Because the NaSi-CaAl interdiffusion is very slow (Grove et al., 1984), the anorthite content will remain fixed, whereas a trace element such as $\mathrm{Mg}$ will try to equilibrate. (c) The equilibrium profile (Mge) of the trace element will depend on the boundary conditions. One alternative is to treat the crystal as a closed system, i.e., no flux between the crystal and the liquid (the approach taken by Zellmer et al., 1999). In this case, the total amount of the trace element in the crystal will remain constant during the diffusion process and will have an equilibrium profile very different from that of $(\mathrm{d})$, where the crystal is allowed to exchange trace element with the liquid (the approach taken in this study in this case taken to be an infinite reservoir). Gray bars represent the physical boundary of crystals.

\section{2. "Equilibrium" profiles}

Zellmer et al. (1999) proposed that the final "equilibrium" state would not be one of complete homogenization of the trace element compositional profile. Rather, the trace element compositions would strive to come to equilibrium with the An content in each zone (which remains unmodified), i.e., there would be a final equilibrium compositional zoning ( Figs. $1 \mathrm{c}, \mathrm{d})$. This expected behavior is somewhat analogous to the "two-liquid partition coefficient" concept introduced for silicate melts by Watson (1976) and Ryerson and Hess (1978). 
However, commencing with compositional distributions such as those illustrated in Figure 1b, it is impossible to obtain profiles such as those illustrated in Figures 1c and 1d by means of a standard formulation of the diffusion equation. In particular, to obtain a "trough" from a "hill," it is necessary to continue diffusion even after the diffusing element has attained a homogeneous distribution, i.e., a flat profile. This behavior may be obtained by so-called uphill diffusion, but uphill diffusion of a trace element in a solid silicate is not generally anticipated from straightforward multicomponent coupling (e.g., see Allnatt and Lidiard, 1993). This prompted us to analyze the process of trace element diffusion in plagioclase in detail, starting from fundamental axioms of irreversible thermodynamics.

\subsection{Driving forces}

The commonly used irreversible thermodynamic formulation assumes that the diffusive flux of a trace element such as $\mathrm{Mg}$ in plagioclase $\left(J_{\mathrm{Mg}}\right)$ is linearly related to its own chemical potential $\left(\mu_{\mathrm{Mg}}\right)$ gradient as well as that of the other constituents of plagioclase, e.g.,

$$
J_{\mathrm{Mg}}=-L_{\mathrm{Mg}} \frac{\partial \mu_{\mathrm{Mg}}}{\partial x}-L_{\mathrm{MgAn}} \frac{\partial \mu_{\mathrm{An}}}{\partial x}-\text { etc. }
$$

where $L_{i j}$ is the phenomenological coefficient with the subscripts indicating the elements of interest, and $x$ is distance. It can be shown that the cross terms in such a formulation are related to the two-atom correlation function of the form $<\mathrm{r}_{\mathrm{i}} \mathrm{r}_{\mathrm{j}}$ (Allnatt and Lidiard, 1993), which is small for two trace elements, and the term involving MgAn can also be ignored to a very good approximation, because the diffusion rate of the An component, which is many orders of magnitude smaller, enters into this term (e.g., see Lasaga, 1998). Therefore, the diffusive flux of $\mathrm{Mg}$ in plagioclase may be well approximated by

$$
J_{\mathrm{Mg}}=-L_{\mathrm{Mg}} \frac{\partial \mu_{\mathrm{Mg}}}{\partial x}
$$

Expanding the chemical potential term in Eqn. 1 by using concentration in units of mass per unit mass, at a given temperature, one obtains

$$
\begin{aligned}
J_{\mathrm{Mg}}=-L_{\mathrm{Mg}} \frac{\partial}{\partial \mathrm{x}}\left(\mu_{\mathrm{Mg}}^{\circ}+\right. & \left.R T \ln C_{\mathrm{Mg}}+\mathrm{RT} \ln \gamma_{\mathrm{Mg}}\right) \\
& =-\mathrm{RT} L_{\mathrm{Mg}} \frac{\partial}{\partial \mathrm{x}}\left(\ln C_{\mathrm{Mg}}+\ln \gamma_{\mathrm{Mg}}+\frac{\mu_{\mathrm{Mg}}^{\circ}}{\mathrm{RT}}\right)
\end{aligned}
$$

where $\mu_{\mathrm{Mg}}$ is the standard-state chemical potential of $\mathrm{Mg}$ and $C_{\mathrm{Mg}}$ the concentration of $\mathrm{Mg}$. The main task is to find a form to express the activity coefficient, $\gamma_{\mathrm{Mg}}$. For a plagioclase crystal equilibrating with a given liquid, this may be obtained by expressions provided by Blundy and Wood (1991) and Bindeman et al. (1998) to describe the compositional dependence of $\mathrm{Mg}$ partitioning. The compositional dependence of trace element partitioning between plagioclase and melt can be approximated by a linear function of $X_{\mathrm{An}}$ (mol fraction of anorthite) and is given by:

$$
\mathrm{RT} \ln \frac{C_{\mathrm{Mg}}^{\mathrm{pg}}}{C_{\mathrm{Mg}}^{4}}=A X_{A n}+B
$$


where $\mathrm{CMgPl}$ is the concentration of $\mathrm{Mg}$ in plagioclase, $\mathrm{CMgl}$ is the concentration of $\mathrm{Mg}$ in the liquid, $\mathrm{T}$ is temperature, and $\mathrm{R}$ is the gas constant. This equation was used by Bindeman et al. (1998) to obtain $A=-26.1( \pm 1.1) \mathrm{kJmol}^{-1}$ and $B=-25.7( \pm 0.7) \mathrm{kJmol}^{-1}$ for $\mathrm{Mg}$. At equilibrium, the chemical potential of $\mathrm{Mg}$ in plagioclase $(\mu \mathrm{MgPl})$ is the same as that of the liquid $(\mu \mathrm{Mgl})$ :

$$
\begin{aligned}
& \left(\mu_{\mathrm{Mg}}\right): \\
& \mu_{\mathrm{Mg}}^{1}=\mu_{\mathrm{Mg}}^{\mathrm{Pl}} \text { and } \mu_{\mathrm{Ng}}^{\circ \mathrm{O}}+\mathrm{RT} \ln C_{1}^{\mathrm{Mg}} \gamma_{\mathrm{Mg}}^{1}=\mu_{\mathrm{Mg}}^{\circ \mathrm{Pl}}+\mathrm{RT} \ln C_{\mathrm{Mg}}^{\mathrm{Pl}} \gamma_{\mathrm{Mg}}^{\mathrm{Pl}} \text {. }
\end{aligned}
$$

On rearranging and setting $\mu^{, 1}{ }_{M g}-\mu^{P}{ }_{M g}=\alpha$, we have

$$
\mathrm{RT} \ln \frac{C_{\mathrm{Mg}}^{\mathrm{Pl}}}{C_{\mathrm{Mg}}^{\mathrm{l}}}=\alpha+\mathrm{RT} \ln \gamma_{\mathrm{Mg}}^{1}-\mathrm{RT} \ln \gamma_{\mathrm{Mg}}^{\mathrm{Pl}}
$$

If we now substitute Eqn. 3 into this equation, we finally obtain

$$
\mathrm{RT} \ln \gamma_{\mathrm{Mg}}^{\mathrm{Pl}}=\alpha+\mathrm{RT} \ln \gamma_{\mathrm{Mg}}^{1}-A X_{\mathrm{Au}}-B .
$$

Substituting this into Eqn. 2, we obtain

$$
\begin{array}{r}
J_{\mathrm{Mg}}=-R T L_{\mathrm{Mg}} \frac{\partial \ln C_{\mathrm{Mg}}}{\partial \mathrm{x}}-\mathrm{RT} L_{\mathrm{Mg}} \frac{\partial}{\partial \mathrm{x}}\left(\frac{\alpha}{\mathrm{RT}}+\ln \gamma_{\mathrm{Mg}}^{1}-\frac{A X_{\mathrm{An}}}{R T}\right. \\
\left.-\frac{B}{R T}+\frac{\mu_{\mathrm{Mg}}^{\circ}}{R T}\right),
\end{array}
$$

where application of the product rule yields

$$
J_{\mathrm{Mg}}=\frac{-R T L_{\mathrm{Mg}}}{C_{\mathrm{Mg}}} \frac{\partial C_{\mathrm{Mg}_{g}}}{\partial x}+L_{\mathrm{Mg}} A \frac{\partial X_{\mathrm{An}}}{\partial x}
$$

because the other terms are independent of distance. The elimination of the term involving $\gamma \mathrm{Mgl}$ requires some clarification. Although $\gamma \mathrm{Mgl}$ of a liquid in equilibrium with a given $C_{\mathrm{Mg}}$ and $X_{\mathrm{An}}$ need not be independent of composition a priori, this is reasonable in the present case because the partitioning of $\mathrm{Mg}$ between plagioclase and liquid has been found to be independent (at least within experimental resolution) of liquid composition (Blundy and Wood 1991 and Bindeman et al 1998). Furthermore, direct measurements of activity coefficients of oxides of several divalent cations (e.g., $\mathrm{FeO}, \mathrm{NiO}, \mathrm{CoO}$ ) in a wide range of silicate liquids have shown them to be independent of/relatively insensitive to compositional variations (Holzheid et al., 1997) when liquid standard states are used, as we have done above. Note that the $\mathrm{Mg}$ flux results from two components - a direct contribution due to $\mathrm{Mg}$ diffusing in response to its own concentration gradient, and a second one related to gradients in An content, which results from the fact that the activity or chemical potential of $\mathrm{Mg}$ in plagioclase depends strongly on the An content, which is zoned in this case. This is somewhat analogous to the vacancy wind effect of Manning (1968) and ignoring this component of the flux could lead to incorrect estimates of timescales. Whether timescales would be under- or overestimated depends on the sign of the second flux term relative to the first one (see below), i.e., the disposition of the An gradient relative to the gradient of $\mathrm{Mg}$ (note also that the sign of the constant $A$ is also important, but for most trace elements it is negative; Blundy and Wood 1991 and Bindeman et al 1998. We emphasize that this dependence of the flux of a trace element on the major element gradient arises not from a direct diffusive coupling. Rather, it is 
the influence of the major element on the chemical potential of the trace element that drives the diffusion of the trace element. Thus, it is not the diffusion coefficient, but the driving force that is changed through the presence of a major element gradient. The final, time-dependent form of the diffusion equation is obtained by the usual procedure of applying the continuity relation to the flux Eqn. 5,

$$
\frac{\partial C_{\mathrm{Mg}}}{\partial \mathrm{t}}=-\frac{\partial J_{\mathrm{Mg}}}{\partial x}=\frac{\partial}{\partial x}\left(\frac{L_{\mathrm{Mg}} \mathrm{RT}}{C_{\mathrm{Mg}}} \frac{\partial C_{\mathrm{Mg}}}{\partial x}-L_{\mathrm{Mg}} A \frac{\partial X_{\mathrm{Ag}}}{\partial x}\right)
$$

and using,

$$
\mathrm{g}, \frac{L_{\mathrm{Mg}} \mathrm{RT}}{C_{\mathrm{Mg}}}=D_{\mathrm{Mg}}
$$

$$
\begin{aligned}
\frac{\partial C_{\mathrm{Mg}}}{\partial \mathrm{t}}=\left(D_{\mathrm{Mg}} \frac{\partial^{2} C_{\mathrm{Mg}_{g}}}{\partial x^{2}}\right. & \left.+\frac{\partial C_{\mathrm{Mg}}}{\partial x} \frac{\partial D_{\mathrm{Mg}}}{\partial \mathrm{x}}\right)-\frac{A}{\mathrm{RT}}\left(D_{\mathrm{Mg}} \frac{\partial C_{\mathrm{Mg}} \frac{\partial X_{\mathrm{An}}}{\partial x}}{\partial x}\right. \\
& \left.+C_{\mathrm{Mg}} \frac{\partial D_{\mathrm{Mg}}}{\partial x} \frac{\partial X_{\mathrm{An}}}{\partial x}+D_{\mathrm{Mg}_{g}} C_{\mathrm{Mg}_{g}} \frac{\partial^{2} X_{\mathrm{An}}}{\partial x^{2}}\right),
\end{aligned}
$$

where $D_{\mathrm{Mg}}$ stands for diffusion coefficient of $\mathrm{Mg}$ in plagioclase. Eqn. 7 describes, via the framework of irreversible thermodynamics, how the concentration gradient of a trace element such as $\mathrm{Mg}$ evolves in a zoned plagioclase crystal where it strives to come to equilibrium with a liquid and a distribution of (rather than a single) An contents. This can easily be extended to two dimensions. In cases where grain size is small enough and crystals are prismatic such that diffusive flux from both ends reach a particular point, compositions will change much faster. Accordingly, ignoring such multidimensional effects can lead to incorrect estimates of timescales. We have implemented a finite difference algorithm to calculate the compositional evolution of $\mathrm{Mg}$ for a number of cases using Eqn. 7.

\subsection{Boundary conditions}

Having obtained a suitable form of the diffusion equation, the next issue that arises is the choice of boundary conditions. Zellmer et al. (1999) assumed that (1) the plagioclase crystal becomes a closed system after growth (insulating boundary conditions with no loss or gain of trace elements) and that (2) the liquid composition with which the trace elements strive to equilibrate in each An zone has a hypothetical composition in equilibrium with the mean composition of the plagioclase (Fig. 1c). We think that condition 1 is unrealistic for a crystal immersed in a melt, which is more likely to exchange elements with the melt. Thus, a fixed (FEC) or variable (VEC) edge composition model is more appropriate (e.g., Chakraborty and Ganguly, 1991). Most noteworthy for the present purposes is the observation that a closed system model underestimates timescales (Chakraborty and Ganguly, 1991). An immediate consequence of this modification of condition 1 is that it reveals condition 2 to be a contrived artificial construct. If the crystal remains open to the exchange of trace elements with the melt, then the liquid composition with which the different parts of the crystal strive to equilibrate should be the last melt in equilibrium with the edge of the crystal. These differences between the two approaches are schematically illustrated in Figures 1c,d. As shown in Figure 1c, this consideration is of nontrivial consequence because the final, "target" profiles for diffusion are very different under these different sets of assumptions (also, see below). Accordingly, a given measured compositional profile represents a very different 
degree of modification (i.e., timescales) under the two schemes. A related consideration may be if and how the interior of the plagioclase crystal responds to the liquid composition. This is accomplished through the relevant point defects; the point defects (e.g., vacancies) that are responsible for the diffusion of a given trace element equilibrate with the liquid at the surface of the crystal. As these always diffuse orders of magnitude faster than the elements concerned (e.g., see Schmalzried, 1995), they allow the interior of the crystal to sense the conditions at the surface. Further evidence that this may indeed be a good approximation to the processes occurring in nature is provided from actual measurements of compositional gradients in natural crystals. Figure 2 shows profiles of anorthite and $\mathrm{Mg}$ in a plagioclase from a basaltic andesite from Volcán Pellado (Tatara-San Pedro volcanic complex; Singer et al 1997 and Dungan et al 2001. Superimposed on the measured profile is a calculated line, wherein we have assumed that the $\mathrm{Mg}$ concentration equilibrated with the melt with which the rim was in equilibrium (e.g., using Eqn. 3) and the An content in each zone, and a given temperature. The correspondence of the calculated and measured Mg profiles shapes is consistent with the contentions above.

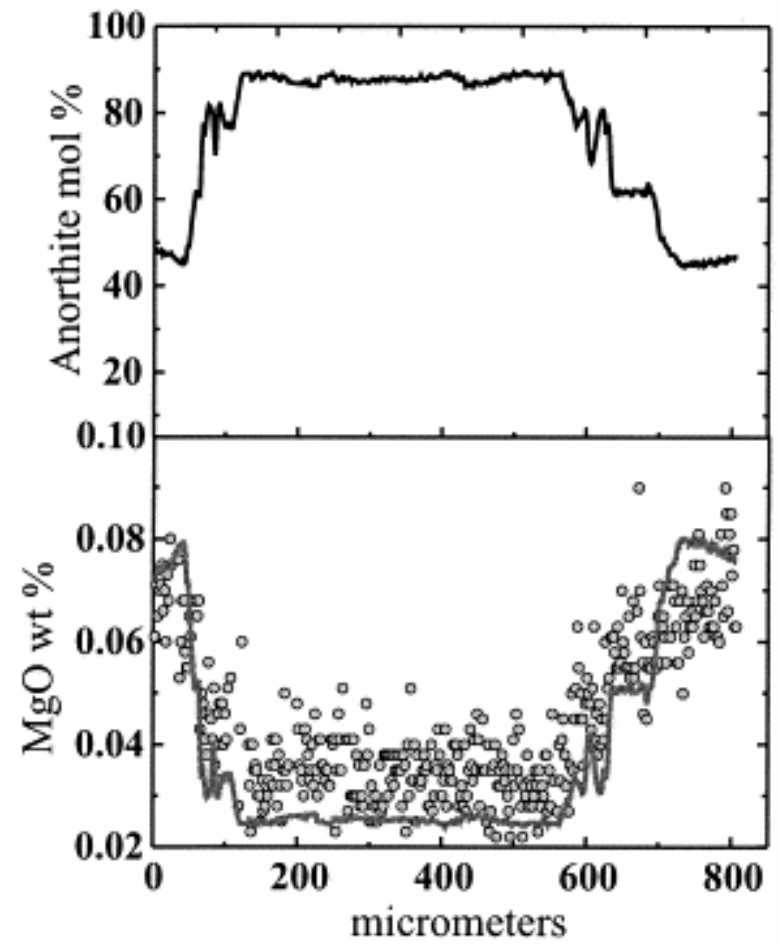

Fig. 2. Anorthite and $\mathrm{Mg}$ concentration profile of a plagioclase crystal from the Tatara-San Pedro volcanic complex (sample EML-9 from Volcán Pellado; Singer et al 1997 and Dungan et al 2001. Note that the Mg profile is almost a mirror image of the An profile and it shows the same profile shape as the calculated equilibrium profile (gray line). The equilibrium concentration was calculated at $900^{\circ} \mathrm{C}$ and by Eqn. 3 (see section 2.4 for details). Plagioclase was analyzed with an electron microprobe (Cameca SX-50) in Orléans (CNRSBRGM) operating with a beam current of $15 \mathrm{nA}$, accelerating voltage of $15 \mathrm{kV}$, and a counting time of $20 \mathrm{~s}$ for $\mathrm{Al}, \mathrm{Si}, \mathrm{Ca}, \mathrm{Na}, \mathrm{Fe}, \mathrm{K}$, and $60 \mathrm{~s}$ for $\mathrm{Mg}$. 


\section{Model parameters}

Before calculating an actual example (section 4), we discuss below the parameters and sources of error that enter the calculations for any given trace element. These are the composition dependent plagioclase-melt partition relations and diffusion coefficients of the element concerned. In addition, each of these may depend on other environmental variables, particularly temperature.

\subsection{Partition Coefficients}

Recent determinations of partition coefficients for different trace elements between plagioclase and melt of a variety of compositions are available (e.g., Blundy and Wood 1991 and Bindeman et al 1998. We have used partition coefficients of $\mathrm{Mg}$ from Bindeman et al. (1998) in our modeling.

\subsection{Diffusion coefficients}

There are a number of determinations of trace element diffusion coefficients in plagioclase and many of them depend on plagioclase major element composition ( $\mathrm{Sr}, \mathrm{K}, \mathrm{Ba}$; Cherniak and Watson 1994; Giletti and Casserly 1994; Giletti and Shanahan 1997 and Cherniak 2002. LaTourrette and Wasserburg (1998) determined $\mathrm{Mg}$ diffusion coefficients in anorthite and showed that it is among the elements that diffuse the fastest, about two orders of magnitude faster than Sr (Cherniak and Watson 1994 and Giletti and Casserly 1994), and approximately seven orders of magnitude faster than $\mathrm{NaSi}-\mathrm{CaAl}$ interdiffusion under "dry" conditions (Grove et al., 1984). Thus, the basis for modeling Mg diffusion relative to a "fixed" An content is justified. Although the Mg diffusion coefficient for albitic plagioclase has not been determined directly, we have estimated it by assuming a compositional dependence similar to that of Sr. Although this estimate does not eliminate the need for direct measurements, it appears to be a reasonable approximation because: (1) the activation energy for diffusion of $\mathrm{Sr}$ is similar to that of $\mathrm{Mg}$ (Giletti and Casserly 1994 and LaTourrette and Wasserburg 1998), so that assuming similar behavior as a function of composition may be a point of departure, and (2) we tried varying the compositional dependence of diffusion coefficient of $\mathrm{Mg}$ keeping the same functional form as that for Sr. Although there is some room for variation, the detailed shape of the profiles themselves preclude diffusion coefficients with arbitrary compositional dependencies. Thus, the equation we have used is

$$
\begin{array}{r}
\mathrm{D}_{\mathrm{Mg}}=\left[2.92 \times 10^{(-4.1 \times A n-3.1)} \exp \left(\frac{-266000 \mathrm{~J} / \mathrm{mol}}{R T}\right)\right] \\
\times 10^{1.2}
\end{array}
$$

where $\mathrm{D}_{\mathrm{Mg}}$ is in microns ${ }^{2} \mathrm{~s}^{-1}$ and $\mathrm{T}$ is in Kelvin.

\subsection{Influence of environmental variables such as temperature}

The discussion so far has ignored the influence of temperature and pressure that can affect the model by influencing the parameters above, partition coefficients, and diffusion rates. The variability in partition coefficients over the temperature interval of interest during growth of a crystal is relatively limited (e.g., Blundy and Wood, 1991) and can be ignored to a first approximation. A far stronger influence of temperature is on diffusion rates. However, it has 
been shown that a nonisothermal problem can always be reduced to an equivalent isothermal one (e.g., Dodson 1973 and Lasaga 1983, and calculations carried out at a constant, characteristic temperature yield the same results (Chakraborty and Ganguly, 1991).

\subsection{Uncertainties}

The main uncertainties in this kind of model arise from uncertainties in temperature determinations and uncertainty in measured diffusion coefficients. Under favorable circumstances, geothermometers are capable of yielding crystallization temperatures within $\pm 25^{\circ} \mathrm{C}$. These translate to uncertainties of less than an order of magnitude in diffusion rates at typical magmatic temperatures and for typical activation energies of around 200 to 300 $\mathrm{kJ} / \mathrm{mol}$. For the case of $\mathrm{Mg}$, a $50^{\circ} \mathrm{C}$ difference modifies the calculated times by a factor of $\sim 3$. Uncertainties in diffusion coefficients are variable, but recent determinations have uncertainties well within a factor of two at magmatic temperatures (for a discussion of data on plagioclase, see Giletti 1994 and LaTourrette and Wasserburg 1998.

\section{Simulations to illustrate the behavior of trace element diffusion in plagioclase}

We carried out a set of model calculations that used the diffusion equations and the boundary conditions outlined above. In each case, a homogeneous plagioclase crystal is considered on which an overgrowth of a second composition is formed instantaneously (e.g., Fig. 1a). We illustrate four possible end-member cases ( Fig. 3): (1) the An and the trace element (e.g., Mg) are normally zoned (higher content in the core than in the rim; Fig. 3a), (2) the An content is normally zoned but the trace element is reversely zoned (higher concentration in the rim than in the core; Fig. 3b), (3) reversely zoned An profile and normally zoned trace element content ( Fig. 3c), and (4) both the An and the trace element are reversely zoned ( Fig. 3d). For comparison, we also show the calculated evolution using the standard formulation where the coupling with An contents is neglected and a simple compositionally dependent diffusion of $\mathrm{Mg}$ (i.e., by using only the first term within square brackets in Eqn. 7) is modeled. In these, we use the same diffusion coefficients and the profiles are illustrated after the same number of time steps. It is apparent how the extent of modification of a compositional profile (i.e., retrieved timescales) depends strongly on the coupling term (e.g., insets of Fig. 3). Details of each simulation are provided in the figure caption; the overall conclusion from a comparison of the two models is that for the early stages of diffusion, the difference between the calculated profiles (and therefore timescales) is relatively small but it increases with increasing extent of diffusion and the maximum difference in timescale retrieved from a given measured profile using the two models can be as much as a factor of 5. Also note the appearance of inflections in the compositional profiles due to uphill diffusion in some simulations ( Figs. 3a,c,d), depending on the nature of the initial Mg and anorthite profiles. Such inflections would be on the order of the resolution of standard ion-probe or laser ablation inductively coupled plasma mass spectrometry analyses and unless special care is taken to detect these, they may go unnoticed, as is seen in the natural samples we simulate below. 

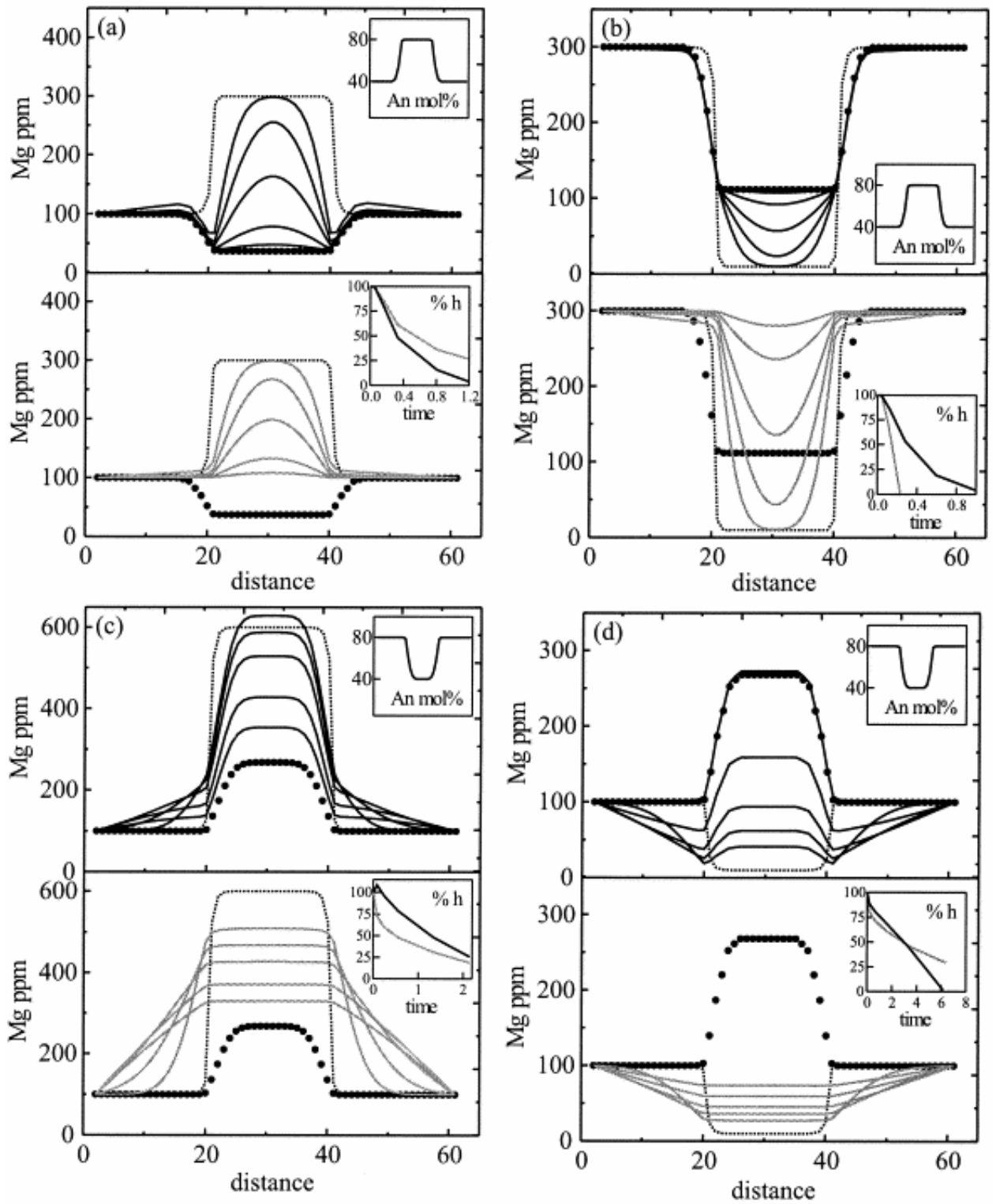

Fig. 3. Model calculations of diffusive equilibration using Eqn. 7 (accounting for coupling of Mg diffusion to An content; profiles in solid lines, upper panels) and a compositional dependent diffusion equation without coupling (i.e., using only the first term in brackets in Eqn. 7; profiles in gray, lower panels). For the dependence of $\mathrm{D}_{\mathrm{Mg}}$ on anorthite content and temperature, Eqn. 8 was used at an arbitrarily chosen temperature of $1100^{\circ} \mathrm{C}$. Dotted lines are the initial $\mathrm{Mg}$ profiles, and larger black dots are the equilibrium profiles. Insets show the An profile and the time evolution for homogenization at the center of the crystal $\left[\% \mathrm{~h}=100 \times\left(\mathrm{C}_{\mathrm{Mg}}-\mathrm{C}_{\mathrm{Mg}}\right.\right.$ equilibrium $) /\left(\mathrm{C}_{\mathrm{Mg}}\right.$ initial $\mathrm{C}_{\mathrm{Mg}}$ equilibrium)]. (a) Anorthite and initial Mg profile are normally zoned. The evolution toward equilibrium is faster when the full equation is used (see inset in lower panel), which means that the calculated times, ignoring coupling, will be longer compared with the case where coupling is accounted. The amount of overestimation depends on the time that has elapsed, on the anorthite content, and on the An gradient. For the example shown in this figure, the time can be overestimated by a factor of 2. (b) Anorthite is normally zoned and initial Mg profile reversely zoned. For this case, Eqn. 7 reaches equilibrium much more slowly compared with the case when coupling is not considered, which means that the calculated times can be underestimated. For the example shown in this figure, the time can be underestimated by a factor of 5. (c) Anorthite is reversely zoned, and initial $\mathrm{Mg}$ profile is normally zoned. The time evolution calculated with coupling can be over- or underestimated depending on the gradient of the anorthite profile. For steep An profiles, times will be underestimated, and for lower An gradients, times can be overestimated. Note also the uphill diffusion at the beginning of the calculation using Eqn. 7. (d) Anorthite and initial Mg are reversely zoned; Eqn. 7 tends to evolve faster than an algorithm without coupling, although it is very sensitive to initial An gradients. 
Finally, Figure 4 shows the effect of multidimensional diffusion when a finite difference adaptation of Eqn. 7 for two dimensions is used. The effects of two-dimensional diffusion become significant for relatively small and prismatic crystals and if this is ignored, in spite of good fits to profile shapes, one would retrieve incorrect timescales. We shall see examples of this effect in our modeling of the natural crystals below. Thus, even though diffusion of elements such as $\mathrm{Mg}$ in plagioclase are found to be only weakly anisotropic (e.g., LaTourrette and Wasserburg, 1998), it is important to consider multidimensional diffusion in cases where substantial compositional modification has taken place.
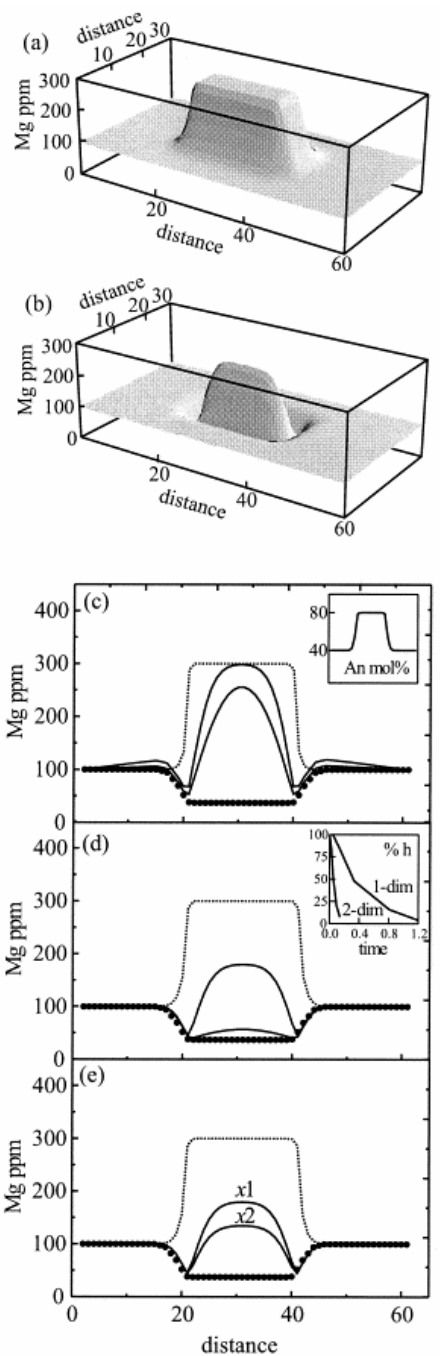

Fig. 4. Model calculation showing the effect of two-dimensional diffusion in small prismatic plagioclase crystals. (a) Initial concentration distribution of $\mathrm{Mg}$ in two dimensions for a crystal with an aspect ratio of 2:1. (b) Concentration distribution of $\mathrm{Mg}$ after some diffusion. (c) Concentration profile calculated using a onedimensional diffusion model at two different times (solid lines). Dotted line is the initial $\mathrm{Mg}$ profile and bold black dots indicate the equilibrium profile. Inset shows the An profile. (d) Concentration profile through the center of the crystal shown in (b) after the same number of time steps as for the one-dimensional model in (c). Note that the time evolution for homogenization (see inset and caption of Fig. 3 for abbreviation) is much faster in two dimensions, and that ignoring such effects can largely overestimate the time. (e) For small and prismatic crystals, the position of the traverse with respect to the center of the crystal is also very important for retrieving the correct timescales. For example, the profile with the label $x 1$ goes right through the center of the crystal shown in (b), whereas the profile labeled $x 2$ is from a location 2 distance units removed from the center at the same point of time. Note that such small difference in position may have a large influence on the profile and thus on the calculated times. 
Differences in behavior may also be expected on the basis of variable compatibility of the modeled element. In the case of a plagioclase crystal in contact with a finite reservoir of melt, the likelihood that the melt reservoir will be depleted during crystallization increases with increasing compatibility of the element of interest (where compatibility refers to the bulk crystallizing mineral assemblage, not only plagioclase). Thus, for a compatible element one would need to apply a VEC model, and in this case, it is necessary to have an estimate of the equilibrating melt volume in addition to the other parameters to estimate the rate of change of the rim composition. For an element behaving incompatibly it is more likely that the melt reservoir is large enough that the composition does not change dramatically and conditions suitable for the application of the FEC model obtain. Thus, incompatible trace elements are likely to be more suitable for this kind of modeling.

The variation in the detailed shape of profiles resulting from such factors as compositional dependence of the diffusion coefficient (profile asymmetry), choice of boundary conditions (closed or open system; i.e., whether flux at the boundary is zero or not) and two-dimensional effects on diffusion point to the nonuniqueness of any single composition in the crystal as an indicator of its thermal history. It is important to fit the shape of the entire profile to obtain robust and meaningful information about timescales. This is well known in the meteorite literature, where the "central composition method" that was used to model taenite-kamacite lamellae in iron meteorites in the 1960s and the 1970s, has been abandoned in favor of fitting the entire compositional profiles, and cooling rates obtained via the older method have been revised (for reviews and discussion, see Rasmussen 1988 and Saikumar and Goldstein 1988.

\section{Modeling natural crystals}

Modeling natural crystals requires some extra steps beyond the forward models we have presented so far. Our approach consists of: (1) estimating the initial concentration distribution of a given trace element within the crystal, (2) estimating the boundary conditions, and (3) carrying out a diffusion calculation with the initial and boundary conditions as noted above to reproduce the observed concentration distributions. We have discussed (3) in detail so far, here we outline the details of (1) and (2). We consider $\mathrm{Mg}$ in plagioclase for illustrative purposes because the faster (e.g., see section 3.2), well constrained (from precise laboratory measurements) diffusion rate of this element makes it ideally suited for this kind of modeling. Further, as shown in Figure 2 and by Ginibre et al. (2002), it is possible to measure $\mathrm{Mg}$ concentration profiles by using long counting times in an electron microprobe, which makes it one of the most accessible trace elements for routine petrologic work. The approach can be extended to any other trace element or isotope.

\subsection{Estimating the Initial Concentration Distribution of a Given Trace Element within the Crystal}

This is inherently difficult to constrain because it is necessary to infer the composition distribution in the crystal before diffusion. The approach that we have taken is to use crystals with large and sharp anorthite changes, from which we infer that the initial profile of the trace element also showed a sharp change (e.g., crystals of Fig. 5). In this case, we still do not know the liquid composition from which these An contents were derived, and this introduces an uncertainty in the inferred initial $\mathrm{Mg}$ content of the zone. For profiles that are not strongly modified and the zones are wide (e.g., a core composition overgrown by a single rim composition), we have taken compositions from the central unmodified portions of a zone as the initial $\mathrm{Mg}$ content, with the form of the distribution dictated by the An profile. This 
situation would apply for modeling crystals with large and sharp changes in anorthite contents-zoning patterns common in plagioclase xenocrysts found in mixed silicic magmas (e.g., Feeley and Dungan 1996; Umino and Horio 1998 and Clynne 1999. In cases where there are oscillations over narrow zones, it becomes more difficult to estimate the initial $\mathrm{Mg}$ distribution and ultimately may require some degree of arbitrariness.
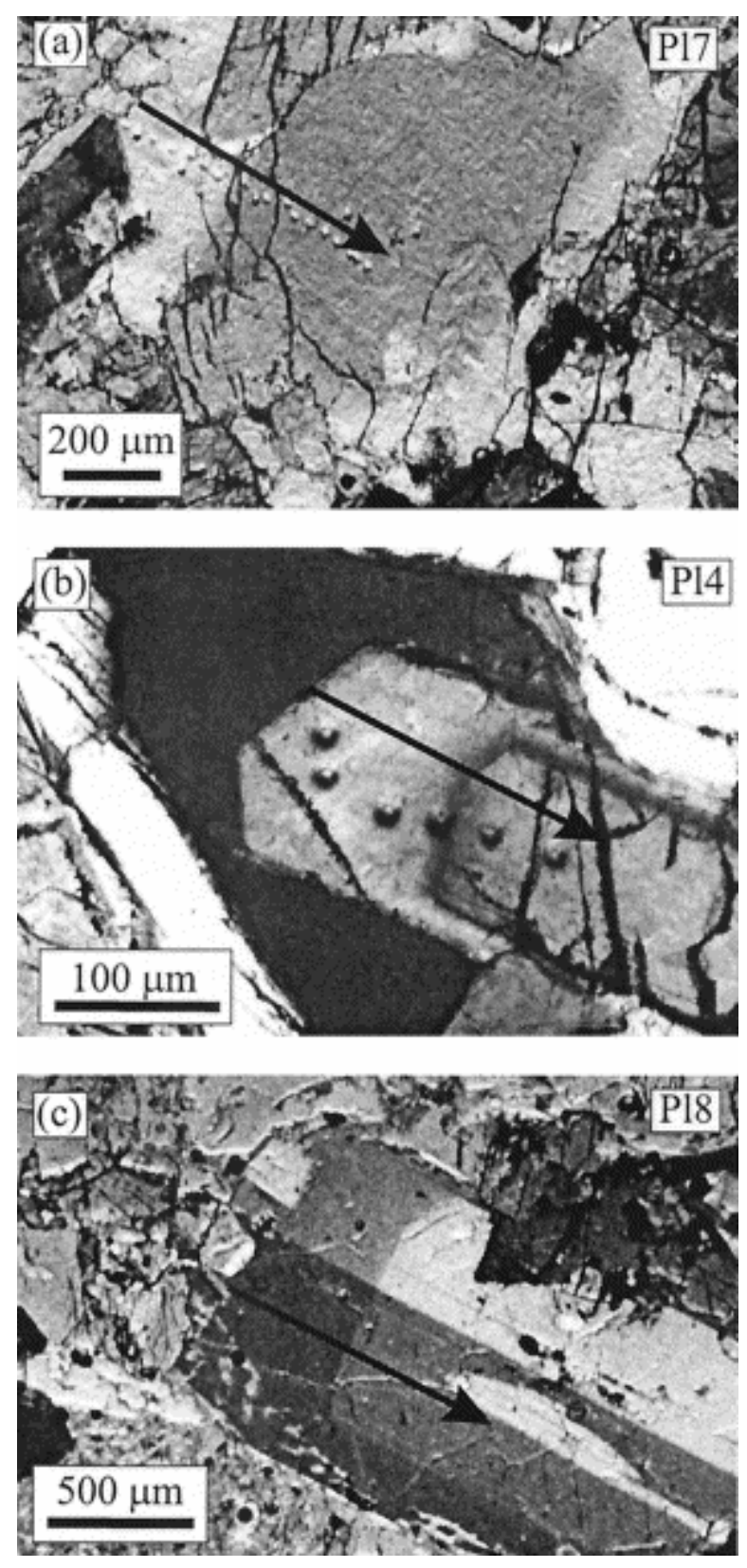

Fig. 5. Photomicrographs (crossed polars) of the three modeled crystals. Note that they all consist of a distinct core and a rim (zones with very different extinction ANGLES = gray levels) despite their different sizes. Arrows illustrate the direction of the electron- and ion-microprobe traverses shown in Figure 6. 


\subsection{Establishing the boundary conditions subject to which diffusion took place}

We calculate the liquid composition in equilibrium with the plagioclase rim (e.g., using Eqn. 3 ) and then carry out the diffusion calculations subject to the condition that the rim always remains in equilibrium with this liquid, i.e., the plagioclase rim/liquid boundary is open to exchange of the trace element concerned; a significant difference with the model of Zellmer et al. (1999). Our approach has the caveat that in some cases, fast growth rates immediately before eruption may prevent plagioclase rims from attaining equilibrium compositions (e.g., Albarède and Bottinga 1972 and Singer et al 1995. However, careful observation allows such late disequilibrium features to be identified as sudden compositional jumps in the profile, and the last composition to have equilibrated with a liquid can be used for modeling. As long as the composition in the plagioclase strives to come to equilibrium with a single liquid composition; real or hypothetical, our approach remains valid. The timescale retrieved, depends strongly on the chosen liquid composition, because this determines the "distance to equilibrium" of the measured profile in a plagioclase. Irrespective of what liquid composition is chosen, we note that all the different An contents cannot be in equilibrium with the same liquid; this situation arises only because of the slow diffusion rates of the anorthite component so that the trace elements that can diffuse try to attain a distribution commensurate with the distribution of An as well as the composition of the liquid surrounding the crystal. After some point of time the An component of plagioclase will also start diffusing and a true overall equilibrium situation would be one where the $A n$ as well as trace elements are homogeneously distributed.

\subsection{Example of application to natural samples: plagioclase zoning profiles from gabbroic xenoliths of Volcan San Pedro}

To illustrate applications of our model we have focused on plagioclase crystals from a suite of gabbroic xenoliths found in a dacite flow of the Holocene Volcán San Pedro (Tatara-San Pedro Volcanic complex, 36 $\mathrm{S}$, Chilean Andes; Singer et al 1997 and Dungan et al 2001. Detailed geochemical analyses and petrography of the xenoliths were presented by Costa et al. (2002), so only a brief summary is given here. The xenoliths are thought to be fragments of a partially crystallized zone that was shattered during the Holocene eruption of Volcán San Pedro, and are probably comagmatic with the zoned silicic magma reservoir (Costa and Singer, 2002). The studied samples are olivine norites to melanorites, they contain interstitial glass, and they show prominent reaction textures involving resorbed olivine, Cr-spinel and clinopyroxene, mantled by orthopyroxene, hornblende, and phlogopite. Plagioclase occurs mainly as euhedral crystals, either as inclusions in orthopyroxene, hornblende, and phlogopite, or in the matrix glass ( Fig. 5). Center to margin electron microprobe analyses were performed across 42 plagioclase crystals. Most plagioclases typically consist of a flat or normally zoned core of $A n_{86}$ to $A n_{75}$, mantled by a normally zoned or flat rim of $A n_{45}$ to $A n_{30}$, occasionally down to $\mathrm{An}_{6}$. The transition between cores and rims is very abrupt, with a decrease of 30 to $40 \mathrm{~mol} \%$ An occurring over a distance of less than $50 \mu \mathrm{m}$. This shift coincides with large and abrupt changes in Fe, K, La, concentrations (Fig. 6). In contrast, $\mathrm{Mg}$ concentrations do not show the large composition changes at the boundary between cores and rims, and in crystal P14 the $\mathrm{Mg}$ concentration profile is almost flat, suggesting that $\mathrm{Mg}$ concentrations have been modified by diffusion. Costa et al. (2002) suggested that the wholerock compositions, textures, mineralogy and the bimodal plagioclase major and trace element compositions of these xenoliths could be explained by a metasomatic event with infiltration of a silicic, water-rich liquid into a crystal-rich framework. In this scenario, the high An cores of the plagioclases crystallized before the metasomatic event, and the albite-rich rims grew from 
the infiltrating evolved liquid. Thus, modeling the trace element concentration profiles provides constraints on the duration of the metasomatic event.

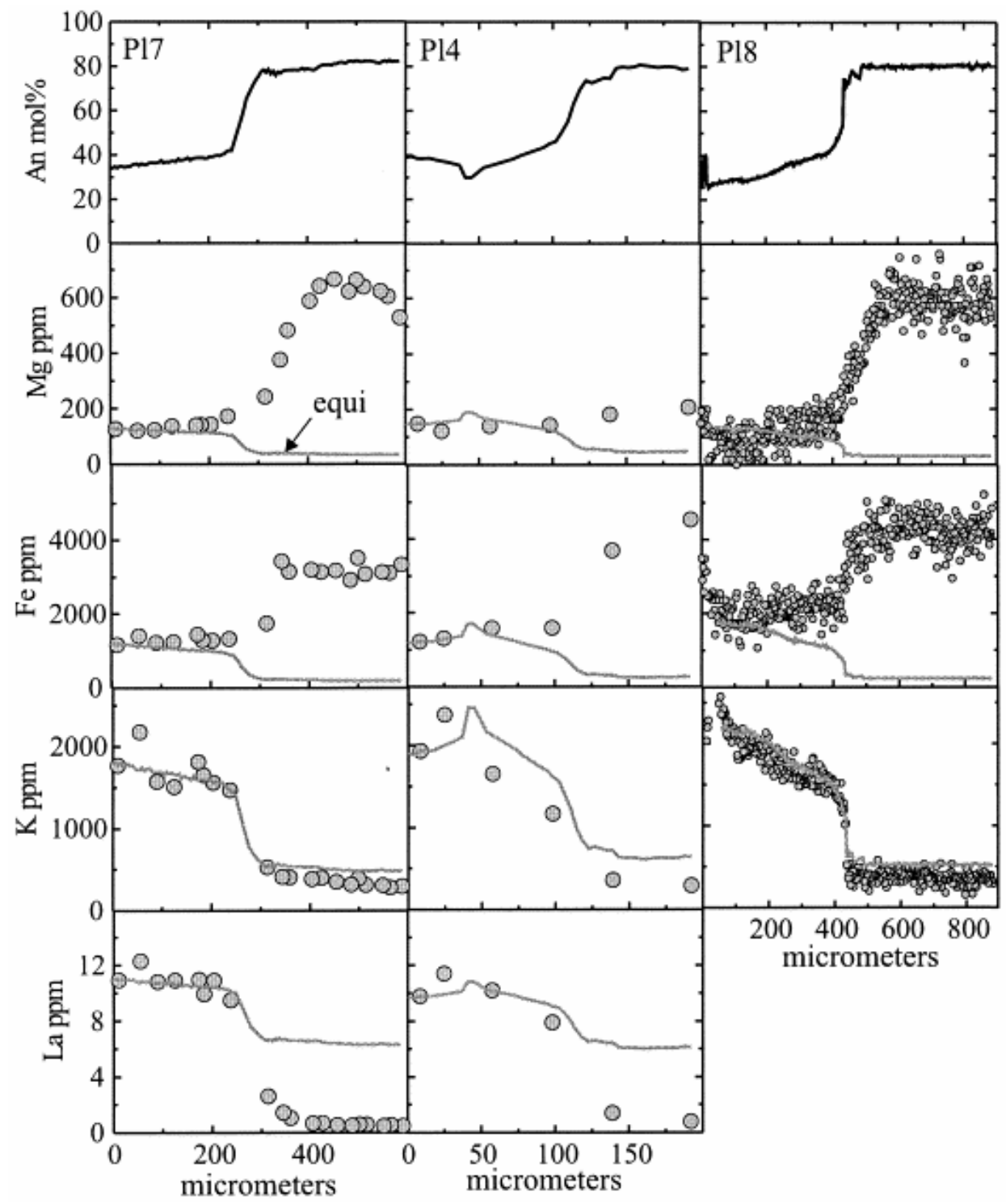

Fig. 6. Major and trace element profiles in three plagioclase crystals. Note the large and abrupt shift in An in the three crystals despite their difference in size. Trace elements mimic the An shift except for $\mathrm{Mg}$, which is almost flat in P14, which suggests that diffusion has modified the Mg profiles. The "equilibrium" concentrations (gray line) were calculated as described in section 2.4 and using a temperature of $850^{\circ} \mathrm{C}$. Photomicrographs of the crystals are shown in Figure 5. Major element plus minor elements in P18 were analyzed with an electron microprobe (Cameca SX-50) of the University of Lausanne and in Orléans (CNRS-BRGM) with the following conditions: $15 \mathrm{nA}$ (beam current), $15 \mathrm{kV}$ (accelerating voltage), with a counting time of $20 \mathrm{~s}$ for Al, $\mathrm{Si}, \mathrm{Ca}, \mathrm{Na}$, $\mathrm{Fe}$, and $\mathrm{K}$ and $60 \mathrm{~s}$ for Mg. Trace and minor element analyses in crystals P17 and Pl4 were performed at the University of Edinburgh with a Cameca IMS-4f ion microprobe with a $\mathrm{O}$ primary beam of net impact energy of $15 \mathrm{keV}(10.7 \mathrm{keV}$ primary and $4.5 \mathrm{keV}$ secondary) and an operating current of 5 to $8 \mathrm{nA}$. The secondary ion accelerating voltage was $4500 \mathrm{keV}$. Only ions with energies falling between 55 and $95 \mathrm{eV}(75 \pm 20 \mathrm{eV})$ were analyzed to reduce molecular ion interferences. Beam diameter ranged between 15 to $30 \mu \mathrm{m}$. The following isotopes were measured: ${ }^{26} \mathrm{Mg},{ }^{30} \mathrm{Si},{ }^{41} \mathrm{~K},{ }^{42} \mathrm{Ca},{ }^{56} \mathrm{Fe},{ }^{139} \mathrm{La}$, plus mass 60 for $\mathrm{CaO}$ overlap on Fe and mass 130.5 to monitor the background. The concentrations were obtained by normalization of mass ${ }^{30} \mathrm{Si}$ to the silica values obtained by electron microprobe analyses. The SRM-610 glass standard was used as a monitor of day-to-day changes in instrumental conditions (the nominal concentrations for SRM-610 are provided in Hinton, 1995). The ion yields for plagioclase relative to SRM-610 were determined with Lake County (LC) plagioclase, an alkali feldspar SHF1 (AF), and Corning glass (CG). The $2 \sigma$ precision for most elements is under $5 \%$ relative. Only La is in some cases slightly above $10 \%$. 


\subsection{Modeling mg diffusion profiles}

To test whether the trace element profiles have been affected by diffusion, we have first calculated the equilibrium compositions by means of the method outlined above (e.g., 2.2 and 2.4) and a temperature of $850^{\circ} \mathrm{C}$ (the lowest temperature obtained by the hornblendeplagioclase geothermometer of Holland and Blundy, 1994). As is apparent from Figure 6, the $\mathrm{K}$ profiles are rather close to the calculated equilibrium values, whereas the rest of the elements are not. This is consistent with the observation that $\mathrm{K}$ diffuses much faster than the other cations (e.g., Giletti, 1994). Consequently, whereas some elements such as La and Fe might provide information about magmatic processes (in this case the abrupt and large difference in La concentrations between core and rims record the arrival of the metasomatic liquid), others such as $\mathrm{Mg}$ or $\mathrm{K}$ may offer clues about the thermal history of such processes.

We have modeled compositional profiles of three plagioclase crystals with sizes ranging from 900 to $200 \mu \mathrm{m}$ (Fig. 5 and Fig. 6). Note from our preceding discussion that we would need different diffusion models to simulate the different crystals; one-dimensional diffusion model would suffice for the larger crystals (e.g., P17 and P18), whereas at least a two-dimensional model should be used for the smaller and prismatic crystals where the core composition is substantially modified (e.g., P14). We have modeled the concentration profiles by two different approaches: (1) Fick's Law based diffusion equation with concentration dependent diffusion coefficients (i.e., accounting for only the direct flux resulting from the first term of Eqn. 7) and (2) the fully developed diffusion equation (Eqn. 7) accounting for the dependence of chemical potential of $\mathrm{Mg}$ in plagioclase on An contents. The results of the best fits using these two types of equations are illustrated in Figure 7 and the retrieved timescales (30 to $225 \mathrm{yr}$ ) are listed in Table 1. The second model reproduces some of the details of the profiles somewhat better, although the uphill diffusion predicted by the model is undetected in the ion probe analyses carried out via standard procedures or the noisy electron microprobe data. The timescales of diffusion required to fit the compositional profiles in the three crystals with very different sizes and consequently, very different shapes of $\mathrm{Mg}$ profiles, are similar when the two models are used, although model 2 consistently requires shorter diffusion timescales to reproduce the observed profiles. Had we chosen to model only one crystal and selected the most evolved profile of the smallest crystal, a simple one-dimensional model would have yielded a timescale of man $200 \mathrm{yr}$ ( Fig. 7c), which is considerably longer than, and inconsistent with, results from the other crystals. With all crystals and factors considered together, data from Table 1 show that a consistent picture is obtained. Our results show that the metasomatic event lasted from a few tens to about a hundred years, and thus the xenoliths remained at high temperatures at best for a few tens of years and this probably places a constraint on the lifetime of the silicic magma reservoir that yielded the spectacular Holocene zoned eruption of Volcán San Pedro (Costa and Singer, 2002). 

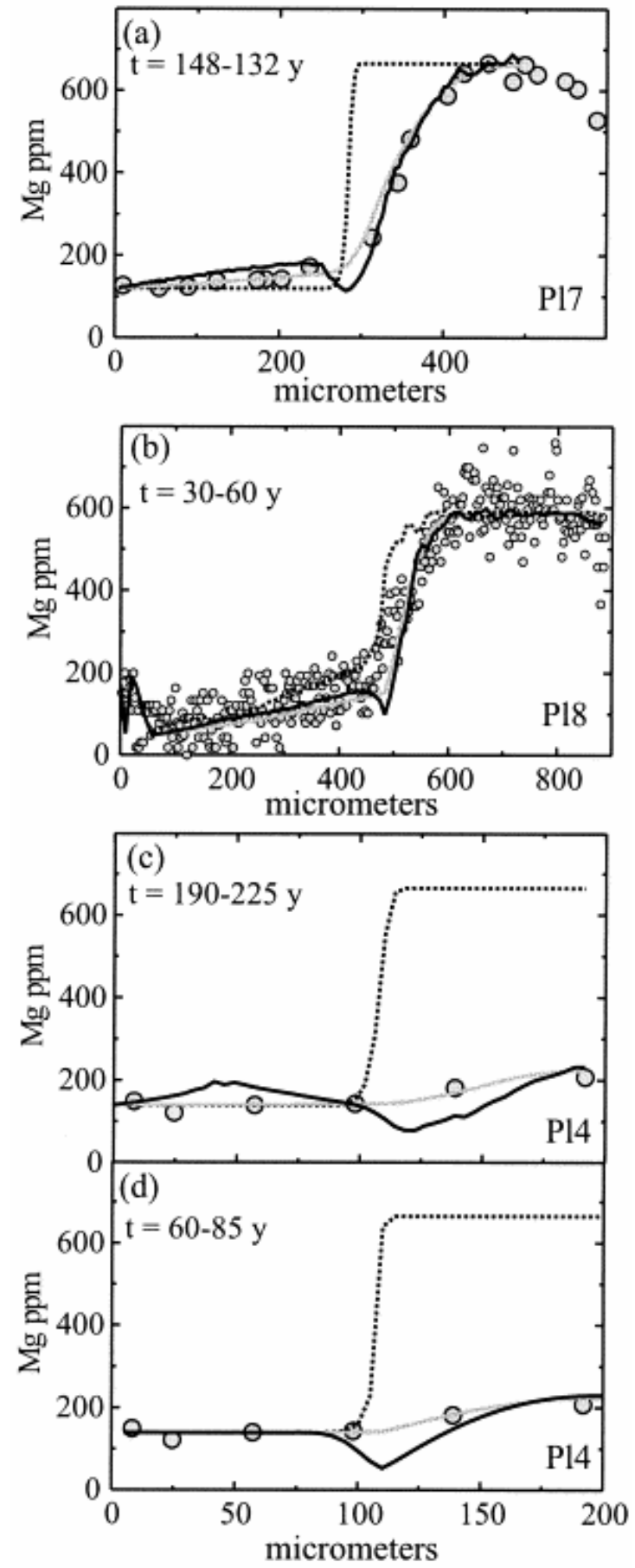

Fig. 7. Modeling results of natural crystals. Dotted lines are the initial Mg profiles; solid lines are from model calculations that use Eqn. 7, and gray lines are from the model that uses only the first term in brackets of Eqn. 7-that is, without considering coupling with major elements. Photomicrographs of the crystals are shown in Figure 5. (a) For crystal P17, both models yield similar times (132 yr using Eqn. 7 and 148 yr, ignoring coupling) and reproduce the natural data quite well. Note that the trough shown by the model using Eqn. 7 is below the resolution of the ion-microprobe analyses. (b) Modeling of crystal P18 gives times ranging from 30 to $60 \mathrm{yr}$, with the shorter times being obtained by Eqn. 7. (c) One-dimensional model for crystal P14. For this crystal, we have used the maximum $\mathrm{Mg}$ concentration of crystal P17 as a proxy for the initial concentration. The profile ignoring coupling gives a better fit to the data and a longer time (225 yr) than the model using Eqn. 7 (190 yr). (d) Model of crystal P14 using a two-dimensional diffusion equation. Note that both models reproduce the data quite well and that the calculated times are about three times smaller than in the one-dimensional model shown in (c). 
Table 1. Summary of calculated times (yr) using Mg diffusion modeling.

\begin{tabular}{lcc}
\hline Crystal & Equation 7 & Comp. dep. ${ }^{\text {. }}$ \\
\hline P17 & 132 & 148 \\
P18 & $30-45$ & $30-60$ \\
P14, 1-dim & 190 & 225 \\
P14, 2-dim & 60 & 85 \\
\hline \multicolumn{2}{l}{ "Model using a compositionally dependent equation (first term in } \\
brackets of Eqn. 7).
\end{tabular}

\section{Conclusions}

We have provided a mathematical formulation to model the diffusive modification of compositional zoning of trace elements in plagioclase. The approach has been illustrated using $\mathrm{Mg}$ zoning in plagioclase crystals from a suite of gabbroic xenoliths. To obtain an internally consistent picture of the thermal history from $\mathrm{Mg}$ concentration profiles in multiple plagioclase grains from the same sample, it was necessary to (1) account for diffusive coupling of trace element to the major element gradient, (2) account for compositionally dependent diffusion rates, (3) account for two-dimensional effects on diffusion in the smaller crystals, and (4) use a realistic boundary condition where the crystal continuously exchanged material with the surrounding melt. Although for the specific profiles that we have modeled the retrieved timescales are very similar for models with or without coupling, this will not always necessarily be the case. As we have shown, the difference in retrieved timescales may increase (depending on the specifics of the system) with increasing extent of diffusion (i.e., as the trace element profile approaches equilibrium with the anorthite profile). More importantly, it is impossible to obtain certain features that may develop when a model without coupling is used (e.g., a final trough from an initial hill-shaped profile). However, once all these features of diffusion were taken into account, we were able to retrieve timescales of $100 \mathrm{yr}$ from the diffusion modeling - a resolution that would be impossible to obtain via any isotopic method applicable to magmatic processes.

\section{Acknowledgements}

This is part of the Ph.D. thesis of F.C., who would like to thank Mike Dungan and Brad Singer for their collaboration and support during the early stages of this project. Many discussions with Mike Dungan are gratefully acknowledged. Thanks also to Andrea Marzoli for pointing out the plagioclase traverse in Figure 2. Reviews by S. Blake, F. J. Ryerson, and an anonymous reviewer helped to improve the clarity of the figures and the text. Richard Hinton and John Craven are thanked for their warm hospitality and support during the ion microprobe analyses. Research was supported by grants from the U.S. National Science Foundation and by Swiss National Fonds (20-42124.94 and 20-49730.96) to Mike Dungan. F.C. acknowledges the financial support from a Marie Curie fellowship (HPMFCT-200000493). S.C. and R.D. acknowledge generous support from the German Science Foundation (DFG) over the period that this research was carried out. 


\section{References}

Albarède, F. and Bottinga, Y., 1972. Kinetic disequilibrium between phenocrysts and host lava. Geochim. Cosmochim. Acta 36, pp. 141-156.

Allnatt, A.R. and Lidiard, A.B., 1993. Atomic Transport in Solids, Cambridge University Press.

Bindeman, I.N., Davis, A.M. and Drake, M.J., 1998. Ion microprobe study of plagioclasebasalt partition experiments at natural concentration levels of trace elements. Geochim. Cosmochim. Acta 62, pp. 1175-1193.

Bindeman, I.N., Davis, A.M. and Wickham, S.M., 1999. 400 my of basic magmatism in a single lithospheric block during cratonization: Ion microprobe study of plagioclase megacrysts in mafic rocks from Transbaikalia, Russia. J. Petrol 40, pp. 807-830.

Blundy, J.D. and Shimizu, N., 1991. Trace element evidence for plagioclase recycling in calcalkaline magmas. Earth Planet. Sci. Lett 102, pp. 178-197.

Blundy, J.D. and Wood, B.J., 1991. Crystal-chemical controls on the partitioning of Sr and Ba between plagioclase feldspar, silicate melts, and hydrothermal solutions. Geochim. Cosmochim. Acta 55, pp. 193-209.

Brophy, J.G., Dorais, M.J., Donnelly-Nolan, J. and Singer, B.S., 1996. Plagioclase zonation styles in hornblende gabbro inclusions from Little Glass Mountain, Medicine Lake volcano, California: Implications for fractionation mechanisms and the formation of composition gaps. Contrib. Mineral. Petrol 126, pp. 121-136.

Chakraborty, S. and Ganguly, J., 1991. Compositional zoning and cation diffusion in garnets. In: Ganguly, J., Editor, , 1991. Diffusion, Atomic Ordering and Mass Transport, SpringerVerlag, pp. 120-175.

Cherniak, D.J., 2002. Ba diffusion in feldspar. Geochim. Cosmochim. Acta 66, pp. 16411650 .

Cherniak, D.J. and Watson, E.B., 1994. A study of strontium diffusion in plagioclase using Rutherford backscattering spectroscopy. Geochim. Cosmochim. Acta 58, pp. 5179-5190.

Clynne, M.A., 1999. Complex magma mixing origin for multiple volcanic lithologies erupted in 1915, from Lassen Peak, California. J. Petrol 40, pp. 105-132.

Cooper, K.M., Reid, M.R., Murrell, M.T. and Clague, D.A., 2001. Crystal and magma residence at Kilauea Volcano, Hawaii: ${ }^{230} \mathrm{Th}-{ }^{226} \mathrm{Ra}$ dating of the 1955 east rift eruption. Earth Planet. Sci. Lett 184, pp. 703-718.

Costa, F., Dungan, M. and Singer, B.S., 2002. Hornblende-and phlogopite-bearing gabbroic xenoliths from Volcán San Pedro $\left(36^{\circ} \mathrm{S}\right)$, Chilean Andes: Evidence for melt and fluid migration and reactions in subduction-related plutons. J. Petrol 43, pp. 219-241. 
Costa, F. and Singer, B.S., 2002. Evolution of Holocene dacite and compositionally zoned magma, Volcán San Pedro, Southern Volcanic Zone, Chile. J. Petrol 43, pp. 1571-1593.

Davidson, J.P. and Tepley III, F.J., 1997. Recharge in volcanic systems: Evidence from isotope profiles of phenocrysts. Science 275, pp. 826-829.

Dodson, M.H., 1973. Closure temperature in cooling geochronological and petrological systems. Contrib. Mineral. Petrol 40, pp. 259-274.

Dungan, M., Wulff, A. and Thompson, R., 2001. Eruptive stratigraphy of the Tatara-San Pedro Complex, $36^{\circ} \mathrm{S}$, Southern Volcanic Zone, Chilean Andes: Reconstruction method and implications for magma evolution at long-lived arc volcanic centers. J. Petrol 42, pp. 555626.

Feeley, T. and Dungan, M., 1996. Compositional and dynamic controls on mafic-silicic magma interactions at continental arc volcanoes: Evidence from Cordón El Guadal, TataraSan Pedro Complex, Chile. J. Petrol 37, pp. 1547-1577.

Giletti, B.J., 1994. Isotopic equilibrium/disequilibrium and diffusion kinetics in feldspars. In: Parsons, I., Editor, , 1994. Feldspars and Their Reactions, pp. 351-382 NATO ASI Series 421. Kluwer .

Giletti, B.J. and Casserly, J.E.D., 1994. Strontium diffusion kinetics in plagioclase feldspars. Geochim. Cosmochim. Acta 58, pp. 3785-3797.

Giletti, B.J. and Shanahan, T.M., 1997. Alkali diffusion in plagioclase feldspar. Chem. Geol 139, pp. 3-20.

Ginibre, C., Wörner, G. and Kronz, A., 2002. Minor-and trace-element zoning in plagioclase: Implications for magma chamber processes at Parinacota volcano, northern Chile. Contrib. Mineral. Petrol 143, pp. 300-315.

Grove, T.L., Baker, M.B. and Kinzler, R.J., 1984. Coupled CaAl-NaSi diffusion in plagioclase feldspar: Experiments and applications to cooling rate speedometry. Geochim. Cosmochim. Acta 48, pp. 2113-2121.

Hinton, R., 1995. Ion microprobe analysis in geology. In: Potts, P.J., Bowles, J.F.W., Reed, S.J.B. and Cave, M.R., Editors, 1995. Microprobe Techniques in the Earth Sciences, pp. 235289 Mineralogical Society Series 6. Chapman and Hall .

Holland, T. and Blundy, J., 1994. Non-ideal interactions in calcic amphiboles and their bearing on amphibole-plagioclase thermometry. Contrib. Mineral. Petrol 116, pp. 433-447. Abstract-GEOBASE | Full Text via CrossRef

Holzheid, A., Palme, H. and Chakraborty, S., 1997. The activities of NiO, CoO and FeO in silicate melts. Chem. Geol 139, pp. 21-38.

Lasaga, A.C., 1983. Geospeedometry: An extension of geothermometry. In: Saxena, S.K., Editor, , 1983. Kinetics and Equilibrium in Mineral Reactions, pp. 81-114 Advances in Physical Geochemistry 3. 
Lasaga, A., 1998. Kinetic Theory in the Earth Sciences, Princeton University Press.

LaTourrette, T. and Wasserburg, G.J., 1998. Mg diffusion in anorthite: Implications for the formation of early solar system planetesimals. Earth Planet. Sci. Lett 158, pp. 91-108.

Liu, M. and Yund, R.A., 1992. NaSi-CaAl interdiffusion in plagioclase. Am. Mineral 77, pp. 275-283.

Manning, J.R., 1968. Diffusion Kinetics for Atoms in Crystals, Van Nostrand.

Nakamura, M., 1995. Residence time and crystallization history of nickeliferous olivine phenocrysts from the northern Yatsugatake volcanoes, Central Japan: Application of a growth and diffusion model in the system Mg-Fe-Ni. J. Volcanol. Geotherm. Res 66, pp. 81-100.

Pan, Y. and Batiza, R., 2002. Mid-ocean ridge magma chamber processes: Constraints from olivine zonation in lavas from the East Pacific Rise at $9^{\circ} 30^{\prime} \mathrm{N}$ and $10^{\circ} 30^{\prime} \mathrm{N}$. J. Geophys. Res 107, p. 10 1029/2001JB000435.

Rasmussen K. L. (1988) Metallographic cooling rates of iron meteorites and planetary thermal models. Ph.D. thesis. Geophysical Institute, University of Copenhagen

Ryerson, F.J. and Hess, P.C., 1978. Implications of liquid-liquid distribution coefficients to mineral-liquid partitions. Geochim. Cosmochim. Acta 42, pp. 921-932.

Saikumar, V. and Goldstein, J.L., 1988. An evaluation of the methods to determine the cooling rates of iron meteorites. Geochim. Cosmochim. Acta 52, pp. 715-726.

Schaefer, S.J., Sturchio, N.C., Murrell, M.T. and Williams, S.N., 1993. Internal ${ }^{238}$ U-series systematics of pumice from the November 13, 1985, eruption of Nevado del Ruiz, Colombia. Geochim. Cosmochim. Acta 57, pp. 1215-1219.

Schmalzried, H., 1995. Chemical Kinetics of Solids, VCH Verlag.

Sigmarsson, O., Chmeleff, J., Morris, J. and López-Escobar, L., 2002. Origin of ${ }^{226} \mathrm{Ra}^{2}{ }^{230}$. Th disequilibria in arc lavas from southern Chile and implications for magma transfer time. Earth Planet. Sci. Lett 196, pp. 189-196.

Singer, B.S., Dungan, M.A. and Layne, G.D., 1995. Textures and Sr, Ba, Mg, Fe, K, and Ti compositional profiles in volcanic plagioclase: Clues to the dynamics of calc-alkaline magma chambers. Am. Mineral 80, pp. 776-798.

Singer, B.S., Thompson, R.A., Dungan, M.A., Feeley, T.C., Nelson, S.T., Pickens, J.C., Brown, L.L., Wulff, A.W., Davidson, J.P. and Metzger, J., 1997. Volcanism and erosion during the past 930 k.y. at the Tatara-San Pedro complex, Chilean Andes. Geol. Soc. Am. Bull 109, pp. 127-142.

Umino, S. and Horio, A., 1998. Multistage magma mixing revealed in phenocryst zoning of the Yunokuchi pumice, Akagi volcano, Japan. J. Petrol 39, pp. 101-124. 
Volpe, A.M. and Hammond, P.E., 1991. ${ }^{238} \mathrm{U}_{-}{ }^{230} \mathrm{Th}-{ }^{226} \mathrm{Ra}$ disequilibrium in young Mt. St. Helens rocks: Time constraint for magma formation and crystallization. Earth Planet. Sci. Lett 107, pp. 475-486.

Watson, B.E., 1976. Two-liquid partition coefficients: Experimental data and geochemical implications. Contrib. Mineral. Petrol 56, pp. 119-134.

Zellmer, G.F., Blake, S., Vance, D., Hawkesworth, C. and Turner, S., 1999. Plagioclase residence times at two island arc volcanoes (Kameni Islands, Santorini, and Soufriere, St. Vincent) determined by Sr diffusion systematics. Contrib. Mineral. Petrol 136, pp. 345-357.

Zellmer, G., Turner, S. and Hawkesworth, C., 2000. Timescales of destructive plate margin magmatism: New insights from Santorini, Aegean volcanic arc. Earth Planet. Sci. Lett 174, pp. 265-281. 